\title{
ERRATUM
}

\section{Erratum to: Shockwave Therapy in Patients with Peripheral Artery Disease}

Marco Matteo Ciccone $\cdot$ Angela Notarnicola $\cdot$ Pietro Scicchitano $\cdot$ Marco Sassara $\cdot$ Santa Carbonara $\cdot$ Mariagrazia Maiorano · Biagio Moretti

(C) Springer Healthcare 2012

Erratum to: Ciccone MM, Notarnicola A, Scicchitano P, et al. Shockwave Therapy in Patients with Peripheral Artery Disease. Adv Ther. 2012;29(8):698-707.

The authors of the above-mentioned paper would like to add the following to the Acknowledgments section of their article:

The authors thank Storz Medical, Kreuzlingen, Switzerland, for financial support in the publication of this paper. Storz Medical had no influence on the design, process, analysis, results, or interpretation of the study data.

The authors thank Springer Healthcare for publishing the correction. 